\title{
Profissionais em Gestão da Pós-Graduação: perfil, competências e atividades na percepção dos secretários dos programas de pós-graduação em Educação
}

\section{Professionals in Post-graduation Management: profile, skills and activities in the perception of the secretaries of Post-graduation Programs in Education}

Los profesionales de gestión de posgrado: perfil, habilidades y actividades en la percepción de los Secretarios de los programas de postgrado en Educación

Silvia Adriana da Silva Soares, MBA em Gestão Empresarial pelo Centro Universitário La Salle (Unilasalle) e secretária do Programa de Pós-Graduação em Educação do Centro Universitário La Salle, Canoas, RS, Brasil. E-mail: silviassadry@gmail.com.

Evaldo Luis Pauly, doutor em Educação pela Universidade Federal do Rio Grande do Sul (UFRGS) e coordenador do Programa de Pós-Graduação em Educação (mestrado e doutorado) do Centro Universitário La Salle (Unilasalle), Canoas, RS, Brasil. E-mail: evaldo@unilasalle.edu.br.

\section{Resumo}

O artigo discute a atuação dos secretários de programas de pós-graduação em Educação, um tema relevante para a gestão da pesquisa no Brasil e ainda pouco estudado. A realização do VIII Fórum de Secretários(as) de Pós-Graduação em Educação da Região Sul permitiu a realização desta pesquisa. Como recurso metodológico, foi desenvolvido um questionário com questões fechadas sobre a identificação (gênero, idade, escolaridade), os conhecimentos necessários para o exercício da profissão, as atividades desenvolvidas e as condições de trabalho do respondente; a questão aberta versava sobre a satisfação dos secretários com sua função e com a instituição. Como resultado, 
constatou-se a complexidade da atuação dos secretários e a necessidade de qualificação desses profissionais para viabilizar o aperfeiçoamento do trabalho administrativo da pós-graduação em Educação.

Palavras-chave: Secretaria da Pós-Graduação. Perfil dos Secretários. Gestão da Pós-Graduação.

\section{Abstract}

The aim of present study was point out the secretary's function in the Education's Post-Graduate Programs, a relevant theme for research management in Brazil and poorly unterstood. The realization of the VIII Meeting of the Secretaries of Education's Post-Graduate in the Brazilian Southern Region, allowed the realization of this research. The methodology used was questionnaire with closed questions approaching identification (gender, age, education), the necessary knowledge to secretary's function, developed activities and working conditions. Therefore, there were open question asked about the satisfaction of Secretaries with its function and institution. The results showed the complexity of the activities of secretaries and the need for qualification of these professionals to enable the perfecting of the administrative work of Postgraduate Education Programs.

Keywords: Post-Graduation's Secretary. Profile of the Secretaries. PostGraduation Management.

\section{Resumen}

El artículo analiza el papel de los secretarios de los Programas de Posgrado en Educación, un tema relevante para la gestión de la investigación en Brasil y todavía aún poco estudiado. La realización del VIII Foro de Secretarios(as) de Posgrado en Educación de la Región Sur, permitió la realización de esta investigación. El recurso metodológico hizo uso de un cuestionario con preguntas objetivas que abordan la identificación (sexo, edad, educación), el conocimiento de la profesión, 
las actividades realizadas y las condiciones de trabajo; la pregunta abierta da cuenta al respecto acerca de la satisfacción del Secretario(a) con su función y con la institución. Como resultado si apunta para la complejidad de las actividades de los (las) secretarios(as) y la necesidad de capacitación de estos profesionales para posibilitar la mejora del hacer administrativo de Posgrado en Educación.

Palabras Clave: Secretaria de Posgrado. Perfil de los Secretarios. Gestión de Posgrado.

\section{Introdução}

O artigo problematiza a função dos secretários de programa de pós-graduação em Educação com o objetivo de identificar como esses colaboradores avaliam sua prática profissional em relação à coordenação e aos corpos docente e discente no que se refere à gestão administrativa e pedagógica desses programas. $\mathrm{O}$ artigo faz um primeiro recorte sobre as atividades, as competências e o nível de satisfação dos secretários e tem como base o fato de que, há 13 anos, secretários dos PPGs em Educação da região Sul do país se encontram regularmente no Fórum de Secretários para compartilhar experiências, estabelecer redes de cooperação e se qualificar profissionalmente. A programação do Fórum de 2014, além da sessão de comunicações, incluiu conferências sobre a Plataforma Sucupira apresentadas pelo Dr. Jefferson Mainardes, da Anped, e pelo Ms. Josenilson Guilherme de Araújo, analista em C\&T do Programa Básico de Educação do Conselho Nacional de Desenvolvimento Científico e Tecnológico (CNPq).

O primeiro seminário de secretários de programa de pósgraduação em Educação da Região Sul aconteceu na Universidade Federal de Santa Catariana, em Florianópolis, entre os dias 27 e 29 de novembro de 2002. O encontro teve como objetivo socializar as experiências desses profissionais, compartilhando dúvidas, questionamentos, avanços e perspectivas, bem como "construir um espaço de discussão para aprofundar o vínculo entre ações burocráticas e pedagógicas no procedimento do Datacapes" (UNIVERSIDADE FEDERAL DE SANTA 
CATARINA, 2002). Desde então, o evento aconteceu em todas as edições da Anped/Sul, agora denominado Seminário de Pesquisa em Educação da Região Sul - Reunião Científica Regional da Anped, contribuindo para a qualificação dos secretários dos PPGs em Educação da Região Sul.

A motivação para o estudo nasceu da experiência dos autores que, na sua prática cotidiana no PPG em Educação, trabalham em conjunto no preenchimento do aplicativo "Coleta de Dados" da Capes e passaram a fazê-lo sob a nova Plataforma Sucupira. A partir dessa experiência profissional, os autores listaram as atividades que desenvolvem para atender às demandas da Plataforma Sucupira. Com base nessa experiência profissional, a primeira autora, em diálogo com alguns colegas do Fórum de Secretários de PPGs em Educação da Região Sul, decidiu aplicar um questionário aos 17 profissionais que participaram do VIII Fórum de Secretários, realizado em 2014.

Assim, o artigo inicia-se com a apresentação do sistema de avaliação da pós-graduação brasileira, descrevendo-o na perspectiva de uma secretária do PPG que auxilia no preenchimento, de forma direta ou indireta, da Plataforma Sucupira. No segundo momento, apresenta os resultados do questionário aplicado aos 17 secretários presentes no VIII Fórum. Essa apresentação esboça um perfil dos secretários. 0 artigo também descreve quais são, na percepção dos respondentes, os conhecimentos necessários para as atividades que eles desenvolvem no PPG. Por último, pediu-se que avaliassem as condições institucionais e indicassem o grau de satisfação que têm ao trabalhar em um PPG na condição de secretário(a).

Os autores estão convictos de que apenas iniciam uma discussão que precisa desenvolver-se dada a importância estratégica da secretaria de um programa de pós-graduação para o processo avaliativo. Afinal, os secretários assessoram o colegiado - a coordenação e os corpos docente e discente - naquilo que se refere às dimensões pedagógicas e administrativas de um PPG. Esses profissionais se constituem como gestores acadêmicos e, de tal perspectiva, dominam um conjunto de conhecimentos, procedimentos e técnicas que viabiliza sua atuação. Dessa forma, o secretário da pós-graduação adquire um 
perfil profissional empreendedor com competências e habilidades que fundamentam sua ação e a tomada de decisões no programa de pós-graduação, em contínua transformação e autoavaliação e que é submetido às exigências da avaliação quadrienal do Sistema Nacional de Pós-Graduação (SNPG) brasileiro.

\section{A avaliação da pós-graduação brasileira}

A Coordenação de Aperfeiçoamento de Pessoal de Nivel Superior (Capes) foi instituída em 11 de julho de 1951, pelo Decreto $n^{\circ}$ 29.741. No início do segundo mandato do governo Vargas, retomou-se o desenvolvimento nacional por meio da industrialização, o que, por sua vez, aumentava a complexidade da administração pública. Nesse movimento, veio à tona a urgência "de formação de especialistas e pesquisadores nos mais diversos ramos de atividades: de cientistas qualificados em Física, Matemática e Química a técnicos em finanças e pesquisadores sociais" (CAPES, 2014). Anísio Spínola Teixeira tornouse o primeiro dirigente da Capes, em 1951, afastando-se da direção do órgão em 1964, devido ao golpe militar. Em 1965, com a publicação do Parecer n 977/65 do Conselho Federal de Educação, de autoria do conselheiro Newton Sucupira (SUCUPIRA, 2005), estabeleceram-se conceitos e critérios para a classificação dos cursos de pós-graduação no Brasil, com base nos quais, na época, a Capes fez um "levantamento" reunindo

informações de 157 entidades cujos resultados revelaram a presença de 286 cursos de aperfeiçoamento e especialização e 96 cursos de pós-graduação dos quais 22 eram de doutorado, 67 de mestrado e 7 de características que não se enquadravam nos critérios estabelecidos para verificação (GUTERRES, 2002).

Esse primeiro levantamento inaugurou o processo de avaliação da pós-graduação no Brasil. Assim, conforme Cury (2005), o Parecer Sucupira "passou a conceituar e normatizar os cursos de pós-graduação no Brasil” (p. 10). Ainda, segundo Sucupira, os interesses práticos e imediatos vão além da pós-graduação e têm por finalidade proporcionar, "dentro da universidade, o ambiente e os recursos adequados para 
que se realize a livre investigação científica e onde possa afirmar-se a gratuidade criadora das mais altas formas da cultura universitária” ( $p$. 164). Para Sucupira, a regulamentação da pós-graduação no Brasil é necessária por

três motivos fundamentais que exigem, de imediato, a instauração de sistema de cursos pós-graduados: 1) formar professorado competente que possa atender à expansão quantitativa do nosso ensino superior garantindo, ao mesmo tempo, a elevação dos atuais níveis de qualidade; 2) estimular o desenvolvimento da pesquisa científica por meio da preparação adequada de pesquisadores; 3) assegurar o treinamento eficaz de técnicos e trabalhadores intelectuais do mais alto padrão para fazer face às necessidades do desenvolvimento nacional em todos os setores (2005, p. 165).

Desde 1965, as principais definições do Parecer Sucupira permanecem vigentes no sistema de avaliação do SNPG coordenado pela Capes. Houve apenas uma breve descontinuidade em 15 de março de 1990, quando o governo Collor extinguiu a Capes por meio da Medida Provisória $n^{\circ}$ 150. A pressão contra a extinção da Capes mobilizou as pró-reitorias de pesquisa e pós-graduação das universidades e as sociedades científicas, e, com apoio do Ministério da Educação, a Capes foi restabelecida na estrutura do MEC pela Lei n ${ }^{\circ}$ 8.028, de 12 de abril de 1990, art. 23, inciso II, alínea f. Entre outras atividades, é responsabilidade da Capes realizar a avaliação da pós-graduação stricto sensu. Esse sistema de avaliação está em contínuo aperfeiçoamento e "serve de instrumento para a comunidade universitária na busca de um padrão de excelência acadêmica para os mestrados e doutorados nacionais" e os resultados desta avaliação são utilizados para formulação e reformulação das "políticas para a área de pós-graduação" (CAPES, 2014). Em 2014, o aplicativo Coleta evoluiu para uma nova plataforma on-line que recebeu o nome de Sucupira em homenagem ao redator do Parecer $n^{\circ}$ 977/65, afinal os principais conceitos de seu parecer estão presentes nessa plataforma, que substituiu o aplicativo Coleta de Dados.

O Fórum de Secretários dos PPGs em Educação da Região Sul foi criado para promover a troca de experiências sobre o preenchimento do relatório Coleta, porém, na atualidade, o Fórum tem "o objetivo de 
discutir questões relativas ao trabalho nas secretarias dos PPGs, bem como instrumentalizá-los para o contínuo aperfeiçoamento da sua ação nos Programas" (PORTAL ANPEDSUL, 2012). Atualmente esse processo de qualificação pode ser acompanhado de forma pública e em tempo real pela Plataforma Sucupira, que, por sua integração com a Plataforma Lattes, permite maior participação individual dos integrantes do PPG no processo de avaliação. Assim, a Plataforma Sucupira pressupõe a responsabilização pessoal de cada docente e de cada discente dos PPGs por meio do preenchimento e da atualização do seu respectivo Currículo Lattes. A responsabilidade institucional pelo preenchimento do relatório na Plataforma Sucupira, no entanto, é da Coordenação do PPG e da direção institucional de pesquisa à qual o PPG está vinculado. A articulação orgânica entre a produção acadêmica individual dos docentes, as linhas de pesquisa do PPG e os discentes é responsabilidade do colegiado, personificado na coordenação. Na prática cotidiana, no entanto, os secretários dos PPGs compartilham dessa responsabilidade quando: a) verificam se os registros acadêmicos e curriculares de discentes e docentes estão lançados adequadamente nos Lattes individuais; b) lançam ou informam aos coordenadores os registros acadêmicos requeridos pela Plataforma Sucupira; c) lançam ou informam os registros de participantes externos; d) controlam os relatos quanto aos convênios internacionais ou nacionais etc. Na vida cotidiana dos PPGs, a coordenação é "passageira”, eleita ou indicada pelo colegiado e nomeada pelo dirigente institucional de pesquisa. Geralmente, conforme o costume da área, o mandato é de dois anos. Na prática, os secretários formam um quadro mais "permanente" de contínua atuação entre os quadriênios das avaliações.

Considerando a rotina dos PPGs em Educação, a secretaria possui melhores condições do que a própria coordenação para desenvolver uma expertise sobre a gestão das informações solicitadas pela Plataforma Sucupira. Desse modo, o modus operandi dos PPGs é o de que o(a) secretário(a) insira na plataforma as informações relacionadas ao cadastro do PPG, aos financiadores de projetos de pesquisa, aos discentes (matrícula nas disciplinas, bolsistas, registro de defesas, cadastro dos avaliadores externos, turmas e divulgação dos textos de teses e dissertações) e às vinculações entre linhas de pesquisa, projetos 
de pesquisa e produções. Em contrapartida, a coordenação articula com o colegiado os textos analíticos e político-pedagógicos da proposta do programa, tendo como base empírica a produção intelectual vinculada às linhas e à inserção acadêmica e social que o coletivo do PPG viabiliza.

A avaliação depende da qualidade e da exatidão das informações inseridas nos campos mais adequados do aplicativo. No sistema Coleta, anterior à Plataforma Sucupira, a mesma informação podia ser inserida em um ou mais campos do aplicativo à escolha do secretário e/ou da coordenação. Essa decisão poderia gerar associações diferentes, aumentando ou reduzindo a relevância dos dados. A partir das informações inseridas no Coleta de Dados, gerava-se automaticamente o relatório, que era entregue aos avaliadores como única fonte para redigir os pareceres indicativos da nota do programa. Com a Plataforma Sucupira, os dados inseridos são os mesmos do antigo Coleta de Dados, sendo a principal mudança o fato de que "a inserção de informações pelos programas de pós-graduação (PPGs) passa a ser contínua e online”. As informações poderão ser inseridas "na Plataforma a qualquer momento, assim que alguma situação é concretizada (por ex. a matrícula ou titulação de um aluno, o cadastro de uma produção intelectual, ou ingresso de um docente)" (CAPES, 2014). Desse modo, o coletivo do PPG pode acompanhar o desenvolvimento do relatório do seu programa e consultar os demais. $\mathrm{O}$ acesso público permite que cada integrante do SNPG participe da construção do processo avaliativo em tempo real. O docente pode corrigir uma informação equivocada a seu respeito ou acerca do PPG inserida na Plataforma Sucupira por intermédio do secretário ou da coordenação.

Os dados na Plataforma Sucupira são preenchidos com informações de natureza:

a) individual - os registros de docentes e discentes nos respectivos Lattes devem ser revisados e ajustados pelos indivíduos orientados pela secretaria, visando adequá-los da melhor forma ao objetivo do PPG em relação a sua própria avaliação;

b) administrativa - dados gerados pela secretaria sobre atividades letivas, fluxo de matrículas, disponibilidade 
de equipamentos, bancas de defesa, resultados, relação com egressos, fluxo de docentes e discente, cadastro de participantes externos, atividades dos grupos de pesquisa, acompanhamento de egressos, etc.;

c) política - textos objetivos do colegiado e/ou da coordenação sobre políticas institucionais de planejamento da pesquisa; resultados de credenciamento, descredenciamento e recredenciamento docente; articulação temática das e nas linhas; projetos de inserção acadêmica nacional e internacional; formação permanente dos docentes; contribuição do PPG à área da Educação; avaliação e projeção da inserção social. O objetivo é demonstrar a organicidade do programa entre linha de pesquisa, projetos de pesquisa, orientações, atividades letivas no PPG e na graduação e, principalmente, a produção intelectual docente e discente que emerge organicamente dessas articulações.

Os resultados da avaliação quadrienal coordenada pela Capes indicam "a qualidade do desempenho e a posição relativa de cada programa no contexto de sua respectiva área" e servem de "referência para as decisões dos órgãos governamentais de investimento na pesquisa e na pós-graduação”, fundamentando as decisões do Conselho Nacional de Educação "sobre quais cursos de mestrado e de doutorado obterão" ou não sua permanência no SNPG e a nota do PPG para o próximo quadriênio (CAPES, 2014). O fato de a avaliação quadrienal resultar na exclusão do programa ou em sua manutenção no SNPG com ou sem aumento de nota gera, por óbvio, intensos conflitos. Tais conflitos justificam o esforço político-pedagógico para estruturar a avaliação sobre critérios objetivos, públicos e anteriores aos procedimentos avaliativos. Esse esforço está sintetizado na ficha de avaliação que “é constituída por um conjunto de 19 itens de naturezas diversas, alguns dos quais visando à regulação do sistema e outros à aferição de qualidade" (CAPES, 2013, p. 3). Os 19 itens da ficha, ao fim e ao cabo, dependem dos dados que cada docente e cada discente registram em seu Lattes individual, grande parte dos quais a secretaria e a coordenação utilizam para preencher a Plataforma Sucupira. 


\section{A pesquisa com secretários}

Para a realização da pesquisa, estruturou-se um questionário com 13 questões fechadas voltadas à caracterização pessoal e uma questão aberta sobre a concepção do respondente acerca do seu trabalho e do PPG. O instrumento foi construído com base em uma lista de atividades cotidianas da secretaria do PPG e da projeção de demandas administrativas geradas pela implementação da Plataforma Sucupira, a partir da experiência laboral da primeira autora. Assim, caracteriza-se a pesquisa como uma primeira aproximação ao objeto de estudo, que são os secretários da pós-graduação. O questionário foi estruturado tendo em vista a produção de um breve perfil desses profissionais, assim como buscou-se também verificar a percepção que possuem sobre as competências e as atividades necessárias às funções que exercem nos programas de pós-graduação em Educação.

Em termos de método, a pesquisa é de natureza qualitativa e quantitativa, porque, segundo Creswell (2010, p. 238), ““...] pode-se obter mais insights com a combinação das pesquisas qualitativas e quantitativas. Seu uso combinado proporciona uma maior compreensão dos problemas de pesquisa". Sendo assim, a abordagem quantitativa servirá para “identificar a população do estudo e também declarar o tamanho dessa população e os meios para identificar os indivíduos na população” (CRESWELL, 2010, p. 180). Já a abordagem qualitativa "proporciona uma lente geral de orientação para o estudo de questões de gênero, classe e raça ou outras questões de grupos [...]" (CRESWELL, 2010, p. 90). Para Yin (2006, p. 137), a análise de dados consiste em "examinar, categorizar, classificar em tabelas, testar ou, do contrário, recombinar as evidências quantitativas e qualitativas para tratar as proposições inicias de um estudo".

Dos 33 PPGs em Educação na Região Sul do Brasil, em 2014, somente 17 autorizaram seus secretários a participar do VIII Fórum de Secretários. Alguns colegas justificaram a ausência sob a alegação de que, quando o convite chegou, não tiveram tempo hábil para encaminhar o pedido de dispensa e de auxílio financeiro a sua Instituição. 
O VIII Fórum de Secretários de Programas de Pós-graduação em Educação da Região Sul realizou-se de 26 a 29 de outubro de 2014, em Florianópolis, Santa Catarina, no campus I, da Universidade do Estado de Santa Catarina (Udesc), concomitantemente com a X Anped Sul Reunião Científica Regional da Anped. A coleta de dados consistiu-se na aplicação de um questionário.

Os 17 Secretários que participaram da pesquisa assinaram um Termo de Consentimento Livre e Esclarecido (TCLE). A propósito, conforme explica Szymanski (2004, p. 12): "a concordância do entrevistado em colaborar na pesquisa já denota sua intencionalidade - pelo menos a de ser ouvido e considerado verdadeiro no que diz -, o que caracteriza o caráter ativo de sua participação [...]”. Dessa forma: "O entrevistado, ao aceitar o convite para participar da pesquisa, está aceitando os interesses de quem está fazendo a pesquisa, ao mesmo tempo em que descobre ser dono de um conhecimento importante para o outro" (SZYMANSKI, 2004, p. 13).

Os dados coletados por meio do questionário foram sistematizados em forma de tabelas, quadros e gráficos, o que permitiu "observar determinados aspectos relevantes e começarmos a delinear hipóteses a respeito da estrutura do fenômeno estudado" (BARBETTA, 2006, p. 69).

\section{O perfil: quem são os secretários}

O gênero dos profissionais que atuam nas Secretarias dos PPGs é marcadamente feminino. Dos 17 secretários presentes, 16 eram mulheres. Pelo contato da primeira autora com os programas ausentes, sabe-se que existem mais dois secretários do sexo masculino atuando nos PPGs da Região Sul. O Gráfico 1 representa a média de idade dos secretários presentes no evento.

A maioria dos secretários (10 deles) situa-se na faixa etária dos 30 aos 49 anos, caracterizando um grupo de servidores com experiência laboral de alguns anos. Apenas três secretários possuem idade inferior a 24 anos e outros três estão na faixa etária entre 25 a 29 anos, e ainda há um secretário com mais de 50 anos. 


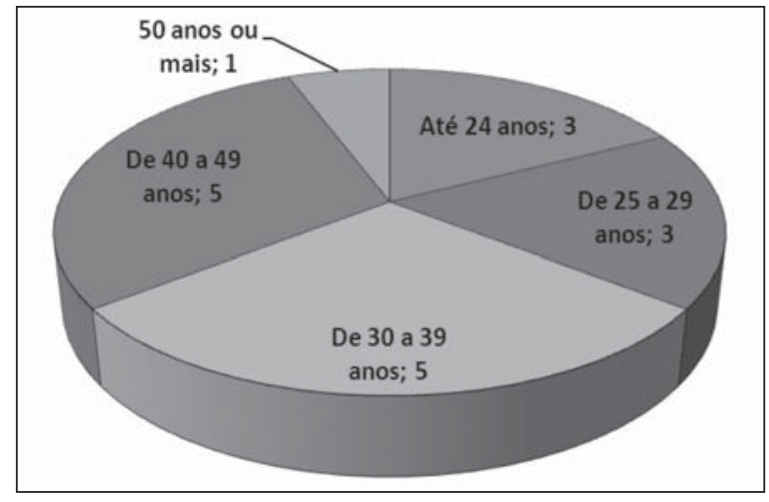

Fonte: elaboração dos autores, 2015.

\section{Gráfico 1. Idade dos secretários}

A maior parte possui formação na área administrativa. 0 secretário com menor escolaridade possui formação de nível médio em curso técnico de Administração, mas ele acrescentou a informação de que, no final de 2014, prestaria vestibular para Administração. Há quatro secretários com formação superior concluída nos cursos de Engenharia Mecânica; Direito; Letras e Secretariado Executivo. Dois possuem nivel superior incompleto e estão cursando Administração. Há sete secretários com curso de especialização em: Gestão de Pessoas; Alfabetização; Gestão Universitária; Gestão Estratégica da Informação; Direito Público; Organização e Administração Pública; Matemática e Física. Dois frequentam cursos de especialização: um em Educação Matemática; e outro em Gestão Empresarial, tendo graduação em Pedagogia. Somente um secretário é mestre em Educação. 


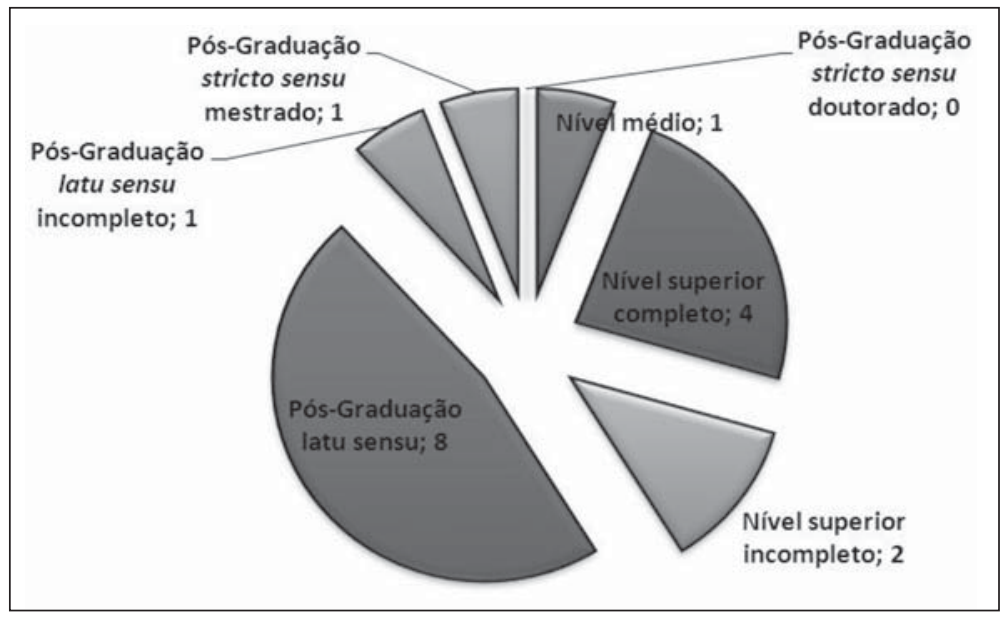

Fonte: elaboração dos autores, 2015

\section{Gráfico 2. Formação acadêmica}

Quanto à formação continuada, quatro secretários não realizaram nenhuma atividade nesse sentido e 13 participaram de cursos de formação nos últimos dois anos. Parece, portanto, que os PPGs da Região Sul incentivam a qualificação permanente de seus secretários. Os cursos de formação continuada informados foram: Plataforma Sucupira; Capacitação para solicitação e concessão de diárias e passagens; Redação oficial; VII Fórum de Secretários na Anped Sul; Formação em Recursos Humanos; Coleta Capes 2012; Formação de professores SEDUC; Formação continuada na instituição com palestras e consultas sobre a Plataforma Sucupira; Plataforma Moodle; Gestão e organização de eventos; Congresso de Secretários das Universidades Brasileiras (CONSUB 2014) e Curso de Secretariado. O questionário solicitava, em seguida, que eles avaliassem em que medida tais atividades foram úteis para a melhoria de sua prática. A maioria dos respondentes assinalou a resposta "muito útil", mas nenhum deles justificou a resposta. Um respondente escolheu a opção "Não contribuiu", justificando que o "ministrante do curso não era bom".

Sobre o tempo de atuação no PPG, pode-se concluir que o cargo de secretário no PPG é relativamente estável. O grupo com atuação inferior a três anos atua em programas recentemente aprovados, portanto, é provável que esteja no PPG desde a sua criação. 


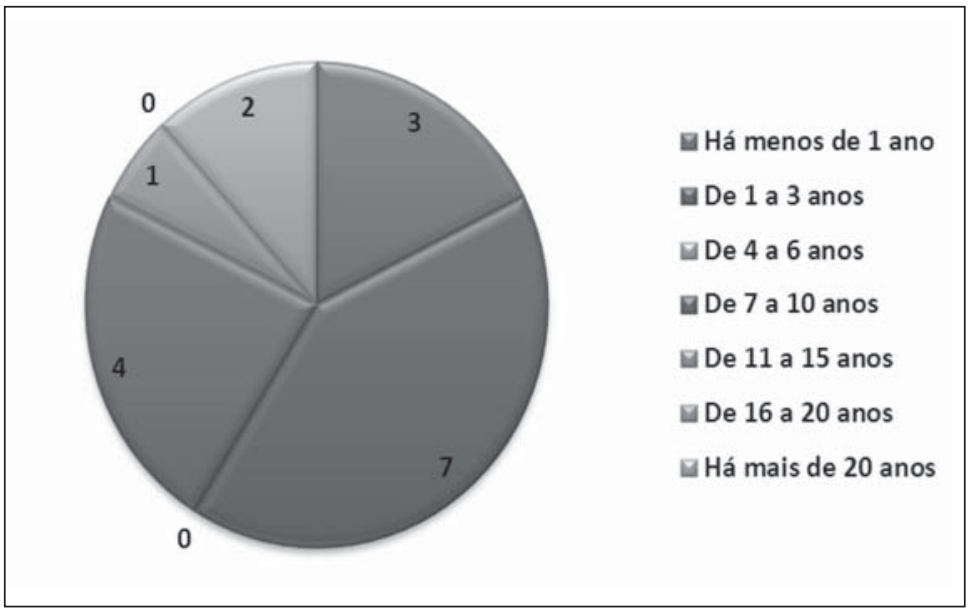

Fonte: elaboração dos autores, 2015.

\section{Gráfico 3. Tempo de atuação como secretário da pós-graduação}

A forma de ingresso dos secretários no PPG indica que sete tiveram seu ingresso na instituição de ensino diretamente pela pósgraduação; quatro ingressaram de cursos de graduação. Os demais entraram no PPG oriundos de outros setores: reitoria, pró-reitora de Ensino, almoxarifado, livraria universitária, coordenação de estágios, centro de Ciências da Educação.

\section{0 trabalho dos secretários}

A pergunta $n^{\circ} 8$ foi respondida a partir de uma lista de conhecimentos para os quais os respondentes deveriam atribuir nota de 1 a 5 conforme o grau de relevância que julgassem necessário para o desempenho profissional, considerando a nota 1 para o conhecimento de menor relevância e 5 para o maior. Para interpretar as respostas, utilizou-se a seguinte padronização: valores menores que 3 não são relevantes, valor 3 é pouco relevante, o valor 4 é relevante e o valor 5 é muito relevante. As respostas a essa questão receberam um tratamento quantitativo para constituir o Ranking Médio (RM) empregando a escala de Likert de 5 pontos. Dessa forma, "para o cálculo do RM utilizou-se o método de análise de escala do tipo Likert apresentado por Malhotra (2001) e utilizado por Tresca e de Rose Jr. (2004) e por Cassiano (2005)", 
(BARBOSA; CAMPANHOL, 2006, p. 12). Para ilustrar esse cálculo, veja-se o exemplo do cálculo para o primeiro conhecimento da lista:

\begin{tabular}{lrllllll}
\hline \multirow{2}{*}{ Noções de Secretariado? } & Notas & 1 & 2 & 3 & 4 & 5 & RM \\
\cline { 3 - 8 } & Frequência & 2 & 2 & 3 & 10 & 4,2 \\
\hline
\end{tabular}

Média Ponderada: $(0 \times 1)+(2 \times 2)+(2 \times 3)+(3 \times 4)+(10 \times 5)=0+4+6+12+50=72$

Logo $\mathrm{RM}=72 /(0+2+2+3+10)=72 / 17=4,2$

\section{Quadro 1. Conhecimentos necessários para desenvolver as atividades}

\begin{tabular}{|c|c|c|c|c|c|c|}
\hline \multirow{2}{*}{ Questões } & \multicolumn{5}{|c|}{ Grau de relevância } & \multirow{2}{*}{$\frac{\text { Ranking Médio }}{\text { RM }}$} \\
\hline & 1 & 2 & 3 & 4 & 5 & \\
\hline Noções de secretariado & & 2 & 2 & 3 & 10 & 4,2 \\
\hline Domínio de língua estrangeira & 4 & 2 & 8 & & 3 & 2,8 \\
\hline Domínio da língua portuguesa & & & 1 & 2 & 14 & 4,8 \\
\hline $\begin{array}{l}\text { Domínio de informática (Word, } \\
\text { Excel, etc.) }\end{array}$ & & & 1 & 6 & 10 & 4,5 \\
\hline $\begin{array}{l}\text { Domínio de informática (sistema } \\
\text { de gestão de informação) }\end{array}$ & 1 & 1 & 3 & 4 & 8 & 4,0 \\
\hline Conhecimento de design & 2 & 7 & 7 & 1 & & 2,7 \\
\hline $\begin{array}{l}\text { Domínio de Leis de Diretrizes e } \\
\text { Bases da Educação (LDB) }\end{array}$ & & 5 & 3 & 2 & 7 & 3,7 \\
\hline Resoluções e portarias do MEC & & 2 & 2 & 2 & 11 & 4,1 \\
\hline Resoluções e portarias da Capes & & & 3 & 2 & 12 & 4,6 \\
\hline $\begin{array}{l}\text { Resoluções e portarias Conselho } \\
\text { Nacional de Educação }\end{array}$ & & 1 & 3 & 4 & 9 & 4,3 \\
\hline $\begin{array}{l}\text { Órgãos de fomento à pesquisa } \\
\text { CNPq, Fapergs e outros }\end{array}$ & & 1 & 5 & 4 & 7 & 4,0 \\
\hline Noções de contabilidade & & 7 & 8 & 2 & & 2,7 \\
\hline $\begin{array}{l}\text { Conhecimento em secretaria } \\
\text { acadêmica }\end{array}$ & & & 1 & 3 & 13 & 4,7 \\
\hline $\begin{array}{l}\text { Conhecimento da Plataforma } \\
\text { Lattes }\end{array}$ & & & 2 & 5 & 10 & 4,5 \\
\hline $\begin{array}{l}\text { Conhecimento da Plataforma } \\
\text { Sucupira }\end{array}$ & & & 1 & 2 & 14 & 4,8 \\
\hline Organização de eventos & & & 6 & 6 & 4 & 3,9 \\
\hline Conhecimento de logística & & 3 & 5 & 7 & 2 & 3,5 \\
\hline $\begin{array}{l}\text { Conhecimento a partir de inter- } \\
\text { câmbio nacional e internacional } \\
\text { com outras instituições. }\end{array}$ & & 5 & 4 & 6 & 2 & 2,9 \\
\hline
\end{tabular}

Fonte: elaboração dos autores, 2015. 
O cálculo do Ranking Médio (RM) indicou que os conhecimentos menos relevantes na visão dos secretários seriam: Domínio de língua estrangeira (2,8); Conhecimento de design (2,7); Noções de contabilidade $(2,7)$ e Conhecimento a partir de intercâmbio nacional e internacional com outras instituições (2,9). Essa avaliação realizada pelos secretários é contrária aos conhecimentos necessários à internacionalização da pós-graduação (língua estrangeira e intercâmbio) que são prioritárias para a área do conhecimento da Educação. Os secretários atribuíram nota superior a 3 para os demais conhecimentos, julgando-os relevantes para o desenvolvimento de suas atividades. Os dois conhecimentos considerados mais relevantes pelos secretários são: Domínio da língua portuguesa e Conhecimento da Plataforma Sucupira, com média de 4,8.

A questão $n^{\circ} 9$ solicitava que os secretários assinalassem as atividades que realizavam, podendo marcar mais de uma. As respostas estão relacionadas no Quadro 2:

\section{Quadro 2. Atividades realizadas}

\begin{tabular}{|c|c|}
\hline Atividades & Respostas \\
\hline $\begin{array}{l}\text { 1. Presta atendimento a clientes presencialmente e por telefone, } \\
\text { dirimindo dúvidas e informando sobre procedimentos, regras e } \\
\text { informações referentes à área. }\end{array}$ & 17 \\
\hline 2. Mantém atualizado o site do Programa. & 17 \\
\hline $\begin{array}{l}\text { 3. Cadastra e mantém atualizados os dados referentes aos discentes } \\
\text { e docentes do programa de pós-graduação (PPG). }\end{array}$ & 16 \\
\hline $\begin{array}{l}\text { 4. Cadastra currículos, turmas, horários e professores das disciplinas } \\
\text { do PPG. }\end{array}$ & 15 \\
\hline $\begin{array}{l}\text { 5. Mantém documentos e arquivos físicos e eletrônicos ordenados e } \\
\text { organizados, com vistas à qualidade do trabalho. }\end{array}$ & 17 \\
\hline 6. Cadastra aproveitamento de disciplinas dos alunos dos PPG. & 15 \\
\hline 7. Emite e/ou assina atestados, históricos, planos de ensino do PPG. & 13 \\
\hline 8. Emite atas de notas finais das disciplinas do PPG. & 14 \\
\hline $\begin{array}{l}\text { 9. Organiza a agenda da área, marca compromissos com envolvidos, } \\
\text { confirma presenças de participantes; convoca envolvidos para } \\
\text { reuniões, informa sobre pauta, providencia a organização de sala } \\
\text { e materiais necessários. }\end{array}$ & 16 \\
\hline $\begin{array}{l}\text { 10. Redige ofícios, circulares internas solicitações e outros documentos } \\
\text { referentes ao PPG. }\end{array}$ & 17 \\
\hline $\begin{array}{l}\text { 11. Cadastra processo de seleção de discentes, recebe documentação } \\
\text { dos candidatos, organiza, encaminha para os avaliadores. }\end{array}$ & 17 \\
\hline
\end{tabular}




\begin{tabular}{|l|c|}
\hline \multicolumn{1}{|c|}{ Atividades } & Respostas \\
\hline $\begin{array}{l}\text { 12. Cadastra avaliações dos candidatos do processo de seleção no } \\
\text { sistema, gera classificação dos candidatos. }\end{array}$ & 16 \\
\hline 13. Emite, publica lista de candidatos aprovados no site. & 16 \\
\hline 14. Faz matrículas dos candidatos aprovados. & 15 \\
\hline $\begin{array}{l}\text { 15. Redige e revisa textos, minutas, correspondências e documentos } \\
\text { em geral; elabora relatórios e apresentações, organizando e } \\
\text { consolidando informações da área, visando subsidiar o processo } \\
\text { decisório. }\end{array}$ & 15 \\
\hline $\begin{array}{l}\text { 16. Elabora, preenche relatório anual de dados referente ao PPG } \\
\text { Educação para a Capes - Coleta de dados (Plataforma Sucupira). }\end{array}$ & 16 \\
\hline 17. Secretaria reuniões do(s) colegiado(s) do PPG. & 15 \\
\hline \begin{tabular}{l} 
18. Redige ata das reuniões do colegiado. \\
\hline 19. Organiza o processo de seleção dos alunos especiais.
\end{tabular} & 16 \\
\hline \begin{tabular}{l} 
20. Faz matrículas de alunos especiais. \\
\hline $\begin{array}{l}\text { 21. Recebe, encaminha solicitações de exames de qualificação, bancas } \\
\text { de defesa. }\end{array}$
\end{tabular} & 17 \\
\hline 22. Organiza eventos referentes ao PPG. & 16 \\
\hline $\begin{array}{l}\text { 23. Redige, arquiva atas de exame de qualificação e defesa de } \\
\text { dissertação ou tese }\end{array}$ & 17 \\
\hline $\begin{array}{l}\text { 24. Contata, confirma, expede documentos para realização de bancas } \\
\text { de qualificação e defesa. }\end{array}$ & 16 \\
\hline $\begin{array}{l}\text { 25. Providencia a divulgação de eventos científicos, com vistas ao } \\
\text { aumento da produção intelectual de docentes e discentes. }\end{array}$ & 16 \\
\hline $\begin{array}{l}\text { 26. Auxilia no preenchimento do APCN referente a propostas de novos } \\
\text { cursos. }\end{array}$ & 16 \\
\hline $\begin{array}{l}\text { 27. Organiza eventos, desde a elaboração da proposta até a execução } \\
\text { das tarefas. } \\
\text { relação, favor descrevê-la: }\end{array}$ & 16 \\
\hline
\end{tabular}

Fonte: elaboração dos autores, 2015.

A pergunta relacionava 27 diferentes atividades, listadas a partir da experiência profissional da primeira autora como secretária. A sistematização das respostas indicou que sete atividades foram marcadas por todos. Outras 10 atividades foram assinaladas por 16 secretários e assim por diante. Portanto, a lista de 27 atividades parece bastante consistente com a realidade da profissão. Os secretários acrescentaram outras atividades que não estavam relacionadas, complementando com mais nove diferentes atividades. Percebeu-se que as atividades dos secretários de PPGs é bem diversificada: 
- Cuidar do laboratório de informática de uso dos alunos;

- Solicitar diárias e passagens e inserir cadastro da viagem e relatório no SCDP;

- Atuar como assistente editorial da revista da instituição;

- Participar de comissão de bolsas (incluindo a elaboração do edital, o processo de inscrição, a seleção, a divulgação etc.);

- Fazer o controle de bolsistas, repassar as informações para o setor financeiro, fazer o controle orçamentário e a elaboração de orçamentos;

- Elaborar projetos de extensão para ser executado por alunos bolsistas;

- Comprar material de expediente, fazer a manutenção de equipamentos e a atualização de todos os sistemas utilizados pela pós-graduação;

- Auxiliar discentes e docentes na atualização do currículo Lattes;

- Organizar prova de títulos do processo seletivo discente.

\section{As condições institucionais e o grau de satisfação dos secretários}

A participação da primeira autora nas duas últimas edições do Fórum permite-lhe supor que uma reclamação recorrente é a de que os regimentos das instituições não preveem a existência de uma secretaria exclusiva para o Programa de Pós-Graduação em Educação. As respostas se dividiram: em 10 deles a Secretaria é compartilhada por vários PPGs e sete secretarias são exclusivas de seus PPGs em Educação.

A próxima pergunta estimulava os secretários a calcularem em que medida as atividades descritas no regimento de seu PPG contemplavam a sua prática efetiva por meio de cinco percentuais: $20 \%$, $40 \%, 60 \%$, $80 \%$ e $100 \%$. 


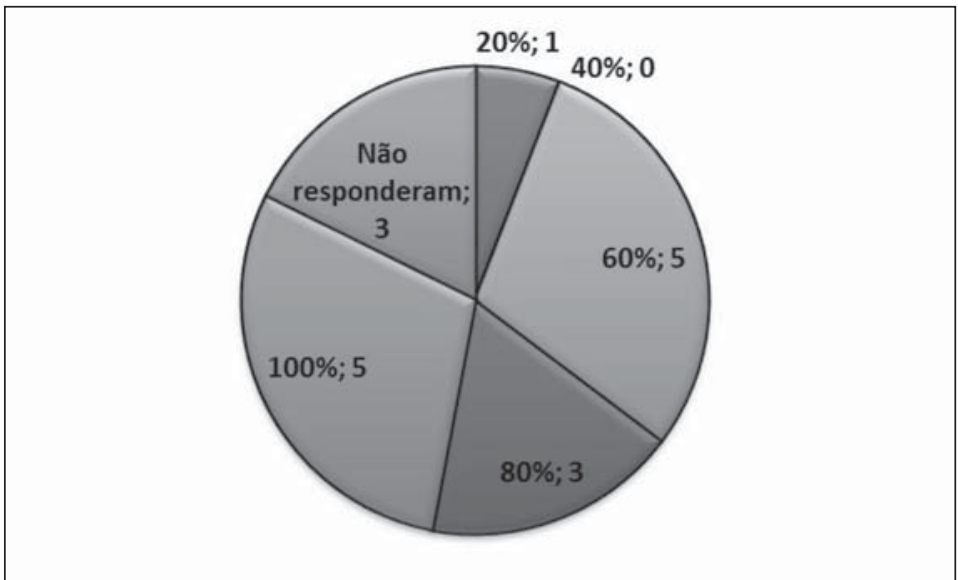

Fonte: elaboração dos autores, 2015

\section{Gráfico 4. Percentual em que as atividades do secretário são contempladas no regimento da instituição}

Apenas um secretário respondeu que suas atividades estavam contempladas em $20 \%$ no regimento do seu PPG, ou seja, que o regimento é insuficiente ao descrever as atribuições do secretário. Para esse respondente, suas funções estariam subentendidas nas da coordenação. De acordo com cinco secretários, o regimento do seu PPG contempla em $60 \%$, ou seja, relativamente bem as atividades que realizam. Desses cinco, três justificaram sua resposta afirmando que muitas "atividades da coordenação são repassadas para a secretaria, que, inclusive, assume responsabilidades que não são suas e não estão descritas no regulamento". Para três respondentes o regimento contempla $80 \%$ de suas atividades; o índice de 100\% foi apontado por cinco secretários. Quanto ao plano de carreira específico para secretários de PPGs, apenas quatro IES o possuem, e duas estão estudando a efetivação de um plano específico para a carreira de secretário. Esse fato parece indicar um fraco reconhecimento institucional dos PPGs quanto ao Secretário. No tocante a salário, pouco mais da metade considera que seu salário está de acordo com o mercado.

A questão aberta perguntava acerca do sentimento do secretário em relação à função e à instituição empregadora. As respostas estão relacionadas no Quadro 3. 


\section{Quadro 3. Sentimento quanto à função e à instituição}

Gosto do trabalho, porém exerço atividades que não são de minha responsabilidade e cargo.

A relação é complicada, visto que há pouca valorização e excesso de atividades desempenhadas.

Sinto-me satisfeito em minha profissão, gosto do que faço. Nossos gestores têm de reconhecer mais o nosso trabalho e não se folgar em deixar para nós o trabalho que compete a eles.

Sinto-me bem valorizado pela coordenação, apesar de achar que a secretaria, em geral, fica sobrecarregada com demandas que não são pertinentes a ela.

Existe o reconhecimento de algumas pessoas próximas em relação às atividades da secretaria, porém não há um apoio institucional forte quanto a um plano de carreira justo, apoio para treinamentos nem reconhecimento financeiro.

Sinto-me bem, porém há necessidade de um maior reconhecimento e de valorização por parte da universidade.

Gosto do meu trabalho e da minha instituição, há problemas, como em todo lugar, mas não trocaria por outro.

Há um reconhecimento da quantidade e da qualidade do trabalho, principalmente por parte dos alunos e dos professores que atuam na pós-graduação. Já outros professores ainda não valorizam, na ideia de que nossas opiniões não têm valor, mesmo quando sobre assuntos que dominamos pelo trabalho na secretaria.

Sinto-me bem, porém sou alvo de qualquer reclamação sobre o PPG, principalmente quando o professor está em atraso e está descontente por seu próprio atraso na atividade.

Por vezes, sobrecarregado, mas considero um bom local de trabalho e com perspectivas de crescimento profissional e pessoal.

Acredito que ainda falta investimento na qualificação dos secretários, assim como valorização da profissão e reconhecimento profissional, além de um plano de carreira consolidado e aplicável.

Acredito que não somos valorizados como gostaríamos. Não temos um plano de carreira específico, o crescimento da pós-graduação é recente, e, por isso, pouco se sabe sobre nossas atribuições, a quantidade de trabalho que temos. Nosso trabalho é muito específico e de pouco conhecimento dos reitores e gestores.

Falta reconhecimento tanto financeiro quanto profissional. A coordenação fica pouco tempo na secretaria, e a maioria dos fogos são apagados pelo próprio secretário, que é obrigado a assumir responsabilidades que não são dele.

Sinto-me muito feliz. Sinto que a instituição onde trabalho tem um ambiente legal e infinitas formas de aprendizado em tudo o que fazemos.

Falta apoio para qualificação em cursos de pós-graduação stricto sensu.

Gosto muito do local onde trabalho, gosto muito do que faço, porém, em relação à instituição, me sinto desvalorizado.

Fonte: elaboração dos autores, 2015. 


\section{Conclusões preliminares}

O artigo pretendia investigar quem são os secretários e como percebem a sua atuação nos PPGs em Educação da Região Sul. Quanto à formação acadêmica, não existe uma formação específica, mas predominou a área administrativa, chamando a atenção o fato de que apenas um secretário possui mestrado em Educação. A análise da forma de ingresso desses profissionais na instituição revela que sete ingressaram diretamente no PPG e 10 por intermédio de outros setores, esse dado talvez demonstre que eles atuaram bem nos outros setores e que o PPG foi uma oportunidade de crescimento profissional.

A percepção dos secretários sobre os conhecimentos necessários para suas atividades indicou que dos 18 conhecimentos listados, os mais relevantes foram Domínio da língua portuguesa e Conhecimento da Plataforma Sucupira, com média de 4,8. Os documentos redigidos pelos secretários são, geralmente, históricos de curso e atas do colegiado que, pela padronização, não exigem tanto domínio linguístico. Sendo assim, a percepção da relevância desses pontos indica que os secretários estão redigindo partes mais significativas da Plataforma Sucupira. Sobre essa questão, percebe-se a necessidade de aprofundamento da pesquisa acerca dos conhecimentos necessários para o exercício da profissão.

A lista de 36 atividades realizadas pelos secretários dos PPGs indica a complexidade da função. Apesar dessa diversidade, apenas sete PPGs estabelecem em seu regulamento a designação de uma secretaria exclusiva. Dez programas não dispõem desse serviço de forma exclusiva. Os regimentos dos PPGs, em geral, não contemplam as funções do secretário, e um plano de carreira específico existe apenas em quatro IES.

Apesar de a maioria dos secretários se queixar do excesso de trabalho, inclusive assumindo tarefas da coordenação, todos os respondentes gostam do que fazem. Alguns dizem receber reconhecimento profissional dos discentes e docentes, mas a maioria ressente-se da falta de incentivo e de reconhecimento por parte da instituição e de seus gestores. Há um sentimento difuso entre os 
secretários no sentido de que seu trabalho é reconhecido pelos discentes, docentes e coordenadores dos PPGs, mas não pelos demais gestores da IES na qual o PPG está inserido.

Pelas conversas informais entre os secretários com maior participação nos Fóruns, sabe-se que alguns, inclusive, preenchem o currículo Lattes de docentes e discentes. Essa informação permitenos sugerir que os PPGs ofereçam oficinas para o preenchimento do Currículo Lattes para docentes e discentes. Em todo caso, os ingressantes no mestrado que não participaram de projetos de iniciação científica, normalmente, não sabem da utilidade acadêmica de planejar o preenchimento do Currículo Lattes, como estratégia fundamental para a consolidação da carreira profissional de pesquisador.

Por outro lado, parece também necessário que a avaliação quadrienal da Capes reconheça como evidência da prática que os secretários são, de fato, responsáveis pelo preenchimento de muitas informações administrativas e quantitativas requeridas pela Plataforma Sucupira. Inclusive porque os coordenadores não trabalham com a maioria dos registros acadêmicos e administrativos. Parece necessário reconhecer a cooperação entre secretário e coordenação para permitir, inclusive, que os relatórios analíticos sejam mais cuidadosamente elaborados pelas coordenações e colegiados.

A experiência do Fórum dos Secretários de Pós-Graduação em Educação da Região Sul, iniciativa dos próprios secretários, tem sido importante para a sua qualificação profissional e tem estimulado o trabalho cooperativo entre eles. As instituições deveriam incentivar a participação de seus secretários, bem como essa atividade como formação continuada poderia ser mais valorizada pela Avaliação Capes. As palestras ministradas ao longo das oito edições do Fórum, as sessões de comunicação propiciadas pelos secretários e a troca formal e informal de experiências entre eles têm contribuído para o aprimoramento de suas atividades e da própria pós-graduação em Educação. O Fórum de Secretários(as) de Programa de Pós-Graduação em Educação poderia ter abrangência nacional, ultrapassando a região Sul. 
Esta primeira aproximação ao objeto da pesquisa - os secretários dos PPGs - revelou que todos os respondentes gostam do que fazem, apesar das queixas sobre o excesso de trabalho, de fazerem mais do que deveriam e até mesmo de assumirem tarefas da coordenação, e também que eles percebem a falta de incentivo e de reconhecimento como um problema significativo para a sua vida profissional. Pela relevância dessa categoria profissional e pela importância que adquiriu no processo de avaliação da Capes, parece-nos prudente e necessária a realização de mais pesquisas sobre esse importante segmento da pós-graduação no Brasil.

Recebido em 24/06/2015

Aprovado em 18/08/2015

\section{Referências}

BARBETTA, P. A. Estatística aplicada às ciências sociais. 5. ed. rev. Florianópolis: Ed. da UFSC, 2006.

BARBOSA, J. P. P.;CAMPANHOL, E. M. A indústria de confecção de Passos/ MG e a capacitação de sua mão-de-obra. REA - Revista Eletrônica de Administração, Franca/SP. v. 5, n. 1, p. 1-16, 2006. Disponivel em: <http://periodicos.unifacef.com.br/ index.php/ rea/article/view/193>. Acesso em: 21 maio 2015.

CAPES - Coordenação de Aperfeiçoamento de Pessoal de Nivel Superior. Relatório de Avaliação 2010-2012 Trienal 2013. Disponível em:<file:///C:/Documents\% 20and\%20Settings/68774370049/Meus\%20 documentos/Downloads/Educa\%C3\%A7\%C3\%A30.pdf >. Acesso em: 10 maio 2015.

História e Missão. Disponivel em: <http:/ /www.capes.gov.br/ sobre-a-capes/historia-e-missao>. Acesso em: 18 abr. 2014.

Educação Documento de Área e Comissão. Disponível em: <http://www.avaliacaotrienal2013. capes.gov.br/documento-de-areae-comissao>. Acesso em: 4 maio 2014. 
Caracterização do Sistema de avaliação da Pós-Graduação. 2014.

Disponivel em:<http:/ /www.capes.gov.br/ cursos-recomendados/91-conteudo-estatico/avaliacao-capes/6871-caracterizacao-do-sistema-de-avaliacao-da-pos-graduacao>. Acesso em: 7 set. 2014.

CRESWELL, J. W. Projeto de pesquisa: métodos qualitativo, quantitativo e misto. 3. ed. Porto Alegre: Artmed, 2010.

CURY, C. R. J. Quadragésimo ano do parecer CFE n 977/65. Revista Brasileira de Educação, Rio de Janeiro, n. 30, p. 7-20, set. / out. /nov. / dez. 2005.

GUTERRES, C. R. J. A Faculdade Interamericana de Educação. Cadernos de Educação Especial / Universidade Federal de Santa Maria. Centro de Educação/ Departamento de Educação Especial/Laboratório de Pesquisa e Documentação. LAPEDOC, Santa Maria, v.1, n. 19, 114 p., 2002. Disponível em: <http://coralx.ufsm.br/revce/ceesp/2002/01/ a11.htm>. Acesso em: 18 abr. 2014.

PORTAL ANPEDSUL. Fórum de Secretários(as) de Programas de Pósgraduação em Educação da Região Sul. 2012. Disponível em: <http:/ / www.portalanpedsul.com.br/home. php?link=secretarios\&sublink=sec retarios>. Acesso em: 6 maio 2014.

SUCUPIRA, N. (Relator). Parecer CFE n 977/65, aprovado em 3 dez. 1965. Revista Brasileira de Educação, Rio de Janeiro, n. 30, p. 162-173, 2005. Disponivel em: <http://www.scielo.br/pdf/rbedu/n30/a14n30. pdf>. Acesso em: 20 jan. 2015.

SZYMANSKI, H. (Org.). A entrevista na pesquisa em educação: a prática reflexiva. Brasília: Liber Livro, 2004.

UNIVERSIDADE FEDERAL DE SANTA CATARINA. Centro de Ciências da Educação. Programa de Pós-Graduação em Educação. I Seminário de Secretários/as de Programas de Pós-graduação em Educação da Região Sul (folheto desdobrável). Florianópolis/SC: Nuclei/CED/UFSC, 2002.

YIN, R. K. Estudo de caso: planejamento e métodos. 3. ed. Porto Alegre: Booman, 2006. 